\title{
Antitumoral Effect of Lobelia Inflata in An Experimental Mouse Model of Melanoma
}

\author{
Nathalia Prata Garcia ${ }^{1}$, Layene Caetano Ireno ${ }^{1}$, Marcello Pardi de Castro ${ }^{1}$, Mirella dos Santos Reis ${ }^{2}$, \\ Luiz Gustavo Gardinassi ${ }^{3}$, Lúcia Helena Faccioli ${ }^{2}$, Cristiane Tefé-Silva ${ }^{1}$ and Karina Furlani Zoccal ${ }^{1 *}$ \\ ${ }^{1}$ Barão de Mauá University Center (CBM), Brazil \\ ${ }^{2}$ Department of Clinical Toxicological and Bromatological Analysis, Faculty of Pharmaceutical Sciences of Ribeirão Preto, University of \\ São Paulo, Brazil \\ ${ }^{3}$ Department of Biosciences and Technology, Institute of Tropical Pathology and Public Health, Federal University of Goiás, Brazil \\ *Corresponding author: Karina Furlani Zoccal, Barão de Mauá University Center (CBM), Brazil
}

\section{ARTICLE INFO}

Received: 慧 January 22, 2020

Published: 慧 January 30, 2020

Citation: Nathalia Prata Garcia, Layene Caetano Ireno, Marcello Pardi de Castro, Mirella dos Santos Reis, Luiz Gustavo Gardinassi, Lúcia Helena Faccioli, Cristiane Tefé-Silva, Karina Furlani Zoccal. Antitumoral Effect of Lobelia Inflata in An Experimental Mouse Model of Melanoma. Biomed J Sci \& Tech Res 25(1)-2020. BJSTR. MS.ID.004154.

Abbreviations: LCL: Lobelia Chinensis Lour; INOS: Inducible Nitric Oxide Synthase; COX-2: Cyclooxygenase-2; TNF- $\alpha$ : Tumor Necrosis Factor- $\alpha$; IL: Interleukin; SEM: Standard Error of Mean; MMPs: Matrix Metallo Proteinases; BFGF: Basic Fibroblast Growth Factor; VEGF: Vascular Endothelial Growth Factor; ANOVA: Analysis of Variance

\section{ABSTRACT}

\section{Background}

Melanoma is a type of skin cancer derived from melanocytes with high degree of malignancy and absence of effective therapy, a fact that motivates the search for new treatments. Medicinal plants provide an interesting source of new compounds with anti-inflammatory and antitumoral properties. The Lobelia inflata plant contains a variety of alkaloids, which have been used as respiratory stimulant, antispasmodic, expectorant, antiemetic. Due these facts, we hypothesized that $L$. inflata may contain compounds with anti-inflammatory and antitumoral activity. Methods: To test this hypothesis, we used an experimental mouse model of melanoma. To evaluate the effects of the $L$. inflata plant extract, mice were subcutaneously inoculated with B16F10 melanoma cells, and subsequently treated with the extract via oral route every 5 days for one month after tumor inoculation. Tumor growth was monitored every 5 days and after 30 days, the animals were euthanized. Blood and peritoneal fluid were collected for total and differential leukocyte counting, as for quantification of cytokines (TNF- $\alpha$, IL- 6 and IL-1 $\beta$ ) and total protein. Results: Administration of the extract reduced inflammatory cell recruitment, edema, and the production of inflammatory cytokines in the peritoneal cavity. Importantly, the plant extract had a significant impact on melanoma growth. Conclusion: These results suggest that $L$. inflata contains compounds with significant antitumoral activity against melanoma.

\section{Highlights}

a) Lihe is not toxic under physiological conditions.

b) Lihe inhibits inflammation during experimental mouse model of melanoma.

c) Lihe reduces tumor size during experimental mouse model of melanoma.

Keywords: Inflammation; Lobelia Inflata; Melanoma; Phytomedicine; Antitumoral

\section{Introduction}

Inflammation is a process involved in the pathogenesis and progression of several diseases [1]. It is a physiological response that protects against pathogenic microorganisms but may result in tissue damage. The inflammatory reaction aims to restore the homeostasis affected by sterile injury or infection [1]. Recent data have expanded the concept of inflammation into a critical component in tumor progression. Several types of cancer originate in sites of chronic infection and inflammation, where inflammatory cells orchestrate the establishment of tumor microenvironment, and thus become indispensable components of the neoplastic process. Currently, a causal relationship between inflammation, innate immunity and cancer is widely accepted, and many of the molecular and cellular mechanisms accounting for this relationship are not well understood [2,3]. In a tumor microenvironment, 
several pro inflammatory mediators participate of a complex signaling process that causes changes in the niche (external microenvironment), changes in the tissue architecture (cells and extracellular matrix), nutritional support and successive mutations in different genes or groups of genes allowing tumor cells to develop [4]. The neoplastic process associated with inflammation includes leukocyte infiltration, production of cytokines such as TNF and IL-2; chemokines such as CCL 2 and CXCL 8; tissue remodeling and neo-angiogenesis [5,6].

Many leukocytes exert anti-proliferative and cytotoxic activities, partially resulting from their ability to secrete reactive nitrogen and hydrogen species (nitric oxide, peroxynitrite, hydrogen peroxide, superoxide) and proinflammatory cytokines (TNF, IL-1, IL-6) [710]. Melanoma is a type of skin cancer derived from melanocytes (melanin-producing cells). The development of melanoma is not fully understood and has been associated to genetic susceptibility and environmental factors such as the destruction of the ozone layer and / or high exposure to ultraviolet rays [11]. Treatments of neoplasms aim to control the tumor microenvironment and eradicate tumor cells. Treatment modalities include surgical procedures, radiotherapy and chemotherapy, which can be used alone or in combination $[2,12]$. Besides the side effects and the high cost of conventional therapies, they may not be effective. Because melanoma exhibits a high degree of malignancy, presents increasing incidence and lacks an effective therapy, the scientific community has been devoted to develop new therapeutics with greater effectiveness and less side effects [13]. Alternatives have been proposed, such as biological therapy that takes into account host defense mechanisms and result in a better understanding of the basic antitumor defense mechanisms [12].

Medicinal plants represent a remarkable source of compounds for the treatment of various human diseases. They are widely explored in modern medicine due to their large range of chemical and biological diversity [14]. The main advantages of using herbal medicines are the low cost, affordability and usually fewer side effects. Studies performed with medicinal plants are very important for confirming their safety and efficacy [15]. The urgent need for new therapeutic agents with greater efficacy and fewer side effects has drawn a great attention to medicinal plants with antiinflammatory and antitumoral properties [13]. Recently, we have demonstrated that Arctium lappa extract has a potent antitumoral activity in vivo [16]. Lobelia inflata is an annual or biannual herbaceous plant belonging to the Campanulaceae family, native of North America, from southeastern Canada (Nova Scotia to Ontario), reaching some states of the United States of America [17]. Popularly, Lobelia is a medicinal plant known as Indian- tobacco, emetic-herb and asthma-herb. The genus also includes the medicinal species L. cardinalis, L. sifilitica and L. chinensis. The base is composed of piperidine alkaloids (lobeline, isolobelin), as well as lobelic acid, chelidonic acid, glycosides, essential oils, resins and fats [18]. Lobelia has a long history of use on respiratory diseases, including asthma, bronchitis, pneumonia, and post-stroke. In homeopathy, is used isolated or in combination with herbs against smoking, muscle relaxation, nausea, vomiting, skin infections (bites, bruises and ringworm), and have properties that relax tissues and reduce spasms $[18,19]$.

Lobelia Chinensis Lour (LCL) is a popular herb that has been used in Chinese medicine for the treatment of lung cancer, inflammation and snakebite [19]. Recent studies have shown that L. chinensis has anti-inflammatory properties, which reduces NF$\kappa \mathrm{B}$ activity and consequently inhibits the expression of Inducible Nitric Oxide Synthase (INOS), Cyclooxygenase-2 (COX-2), Tumor Necrosis Factor- $\alpha$ (TNF- $\alpha$ ), Interleukin (IL) 6$)$, both in vitro and in vivo [20]. In addition, isolated components of the Lobelia plant present antioxidant action in vitro, and hepatoprotective effects in vivo [21]. Because of the anti-inflammatory effects of Lobelia, we hypothesized that it also presents antitumoral activity. Here, we analyzed the potential of the L. Inflata Hydroalcoholic Extract (Lihe) to protect against development of melanoma in an experimental mouse model inoculated with the B16F10 cell line. We observed that it affected the number of circulating leukocytes and suppressed cellular recruitment into the peritoneal cavity. In addition, Lihe inhibited the production of pro-inflammatory cytokines and significantly reduced tumor growth. Collectively, these results indicate that $L$. inflata should be further explored for the development of new antitumoral drugs.

\section{Material and Methods}

\section{Animals}

Male or female Balb/c mice (6-8 weeks old; weighing approximately $20 \mathrm{~g}$ ) were maintained at the animal facility of Barão de Mauá University Center (São Paulo, Brazil). The mice were maintained in the animal facility of a room at $25^{\circ} \mathrm{C}$, with a $12 \mathrm{~h} / 12$ $\mathrm{h}$ light/dark cycle, and provided with free access to food and water. All experiments were approved and conducted in accordance with the guidelines of the Ethics Committee on Research and Animal Experimentation of Barão de Mauá University Center (process \#253/16).

\section{Cell culture}

Melanoma cells of the B16F10 line were cultured in culture medium and, once confluent, in the exponential growth phase, were counted and adjusted to the concentration of $10^{6}$ cells $/ 0.1 \mathrm{~mL}$ of incomplete DMEN medium (Dulbecco modification of Minimum Essential Media). This procedure was carried out in the laboratory of Prof. Dr Lúcia Helena Faccioli, Faculty of Pharmaceutical Sciences of Ribeirão Preto, University of São Paulo.

\section{Preparation of Lobelia Inflata Hydroalcoholic Extract}

The extract of L. inflata was obtained from $100 \mathrm{~g}$ of ground and dry bark, dissolved in $1 \mathrm{~L}$ of $70 \%$ ethanol (JT Baker, Belo Horizonte, Brazil). A dark bottle conditioned at room temperature was used 
for 72 hours with daily shaking, and the extract was then filtered on filter paper. The filtrate was dried using a rotary evaporator (Eppendorf Vacuum Concentrator Plus, Hamburg, Germany). The dried extract was weighed and suspended in $997 \mu \mathrm{L}$ PBS (phosphate-buffered saline) and $3 \mu \mathrm{L}$ of DMSO (Dimethyl sulfoxide, Sigma-Aldrich, Missouri, USA) until a final concentration of $1 \mathrm{~g} /$ $\mathrm{mL}$ was obtained. This extract was filtered and stored in $500 \mu \mathrm{L}$ aliquots at $-20^{\circ} \mathrm{C}$ in a freezer. Plant samples were collected in the city of Uberaba, state of Minas Gerais, Brazil (Lat. -19.743623, Long -47.828514). The specimens were analyzed and identified by Prof. Dr Milton Groppo and deposited in the herbarium of the Faculty of Philosophy, Sciences and Letters of Ribeirão Preto, University of São Paulo.

\section{Tumor Inoculation and Lihe Treatment}

First, 7 animals per experimental tumor groups were trimmed at the dorsal region with the aid of the Panasonic shaver (approximately $1.5 \mathrm{~cm}$ /diameter). On the following day of the experiment, cultured B16F10 melanoma cells exhibiting an exponential growth phase were counted and adjusted to the concentration of $10^{6}$ cells $/ \mathrm{mL}$. Each animal received a subcutaneous a suspension containing B16F10 cells in $0.1 \mathrm{~mL}$ of incomplete DMEN medium. After the tumor inoculation, the control group received only water $(100 \mu \mathrm{L}$ via oral route), containing the same amount of alcohol present in the hydroalcoholic extract every 5 days for 30 days. The treated group received Lihe (300 mg/kg v.o.) every 5 days for 30 days. Animals were sacrificed after 30 days of tumor injection, and blood and peritoneal fluid were collected from these animals for total and differential cell count and for quantification of inflammatory mediators. The experiments were performed twice.

\section{Tumor Evaluation}

Tumor growth and body weight were monitored every 5 days after implantation of B16F10 melanoma cells. The volume of the tumor mass was calculated according to the formula: tumor volume = (length $\mathrm{x}$ height $\mathrm{x}$ width) $/ 2$ and its dimensions $(\mathrm{mm})$ were calculated with the aid of a pachymeter [22].

\section{Leukocyte Counting in The Peritoneal Cavity and in the Peripheral Blood}

Blood samples were obtained from the mice previously anesthetized with ketamine/xilasin by the retro-orbital plexus with the aid of the Pasteur pipette containing heparin. Next, the animals were euthanatized in a $\mathrm{CO}_{2}$ chamber and $3 \mathrm{~mL}$ of PBS was added into the abdominal cavity, which was gently massaged for $1 \mathrm{~min}$. The peritoneal fluid was collected using a syringe with a needle inserted into the inguinal region. Blood and peritoneal cells were counted in Turk's solution using Neubauer chambers. Differential leukocyte counts were performed using cytospin preparations stained with commercial kit based on the Romanowsky staining procedure (Panótico ${ }^{\circledR}$ Laborclin, Paraná, Brazil). A hundred cells were counted in different fields, with an increase of $100 x$, under an optical microscope. After total and differential cell count, the peritoneal fluid was centrifuged for $10 \mathrm{~min}, 10^{\circ} \mathrm{C}, 400 \mathrm{~g}$ and the supernatant were stored at $-20^{\circ} \mathrm{C}$ for further quantification of cytokines and total protein.

\section{Protein Quantification}

Total proteins were quantified in the cell-free peritoneal fluid by Coomassie protein assay reagent (Rockford, USA), according to the manufacturer's instructions.

\section{Cytokines Quantification}

TNF- $\alpha$, IL- 6 and IL-1 $\beta$ concentrations in the peritoneal fluid were quantified by enzyme-linked immunosorbent assay (ELISA) using specific antibodies (purified and biotinylated) and cytokine standards, according to the manufacturer's instructions (R \& D Systems, Minneapolis, USA). Optical densities were measured at $405 \mathrm{~nm}$ in a microplate reader (mQuant, Biotek Instruments Inc.). Cytokine concentrations were determined using a standard curve created with the appropriate recombinant cytokine (expressed in $\mathrm{pg} / \mathrm{mL})$.

\section{Statistical Analysis}

Statistical analyses were performed using GraphPad software (San Diego, CA, USA). Data were expressed as mean \pm Standard Error of Mean (SEM). The differences between any two groups were evaluated using two-tailed Student's t-test. For comparison of multiple groups, we performed one-way Analysis of Variance (ANOVA) followed by Tukey's test when appropriated. Values of $\mathrm{p}<$ 0.05 were considered significant.

\section{Result}

\section{Lihe Does Not Alter the Number of Cells Under Physio- logical Conditions, But It Reduces Neutrophils in Tumor}

\section{Conditions}

Before starting the experiments to evaluate the antitumoral activity of the extract, we evaluated the weight of Balb/c mice receiving the dose chosen for the treatment ( $300 \mathrm{mg} / \mathrm{kg}$ v.o.) for 30 days. As expected, the dose of $300 \mathrm{mg} / \mathrm{kg}$ of Lihe did not interfere with the feeding of the animals, since there were no statistical differences in the weight when compared to the control group, which received only the vehicle by oral route (Figure 1). Balb/c mice treated with Lihe $(300 \mathrm{mg} / \mathrm{kg}$ v.o.) for 30 days exhibited a significant increase in the number of total leukocytes (Figure 2a) and neutrophils (Figure 2b) in the peritoneal cavity, when compared to control group. However, the number of total leukocytes (Figure 2c) and neutrophils (Figure 2d) in the peripheral blood was equivalent to control values. Next, the in vivo effects of Lihe (300 mg/kg, v.o.) treatment were evaluated after subcutaneous inoculation of B16F10 melanoma cells. As expected, the animals receiving B16F10 cells and vehicle exhibited increasing numbers of leukocytes and neutrophils in the peritoneal cavity and peripheral 
blood (Figures 3a-3d). Lihe treatment after B16F10 injection significantly decreased the number of total leucocytes (Figure 3a) and number of neutrophils (Figure $3 \mathrm{~b}$ ) present in the peritoneal cavity, with reductions of 23 and 49\%, respectively. There were no significant alterations in the numbers of total leukocytes in the peripheral blood after Lihe treatment of tumor inoculated animals (Figure 3c), but treatment had a striking effect in the number of neutrophils after tumor injection (Figure $3 d-47 \%$ of inhibition).

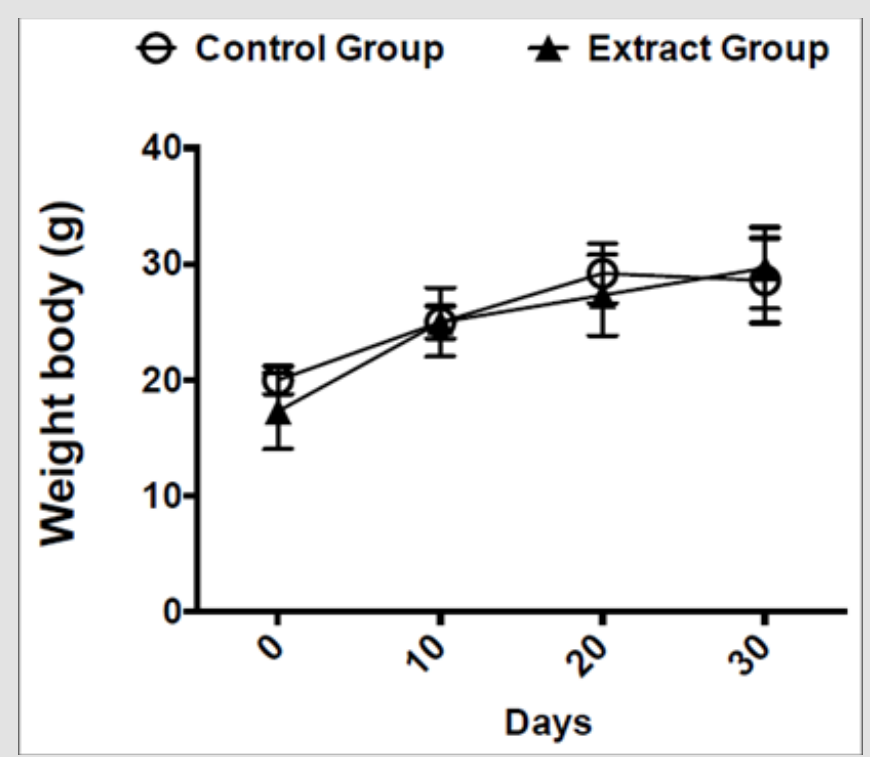

Figure 1: Evaluation of the effects of Lihe over mice body weight. The mice received $100 \mu \mathrm{L}$ of vehicle (control group) or Lihe $(300 \mathrm{mg} / \mathrm{kg}$, v.o.) every 5 days for 30 days. The control group received water $(100 \mu \mathrm{L}, \mathrm{v} . \mathrm{o}$.$) , containing the same amount of$ alcohol present in the extract. The animals are weighed before and every 5 days of treatment to monitor their weight. The graph represents the average weight of the animals every 10 days.

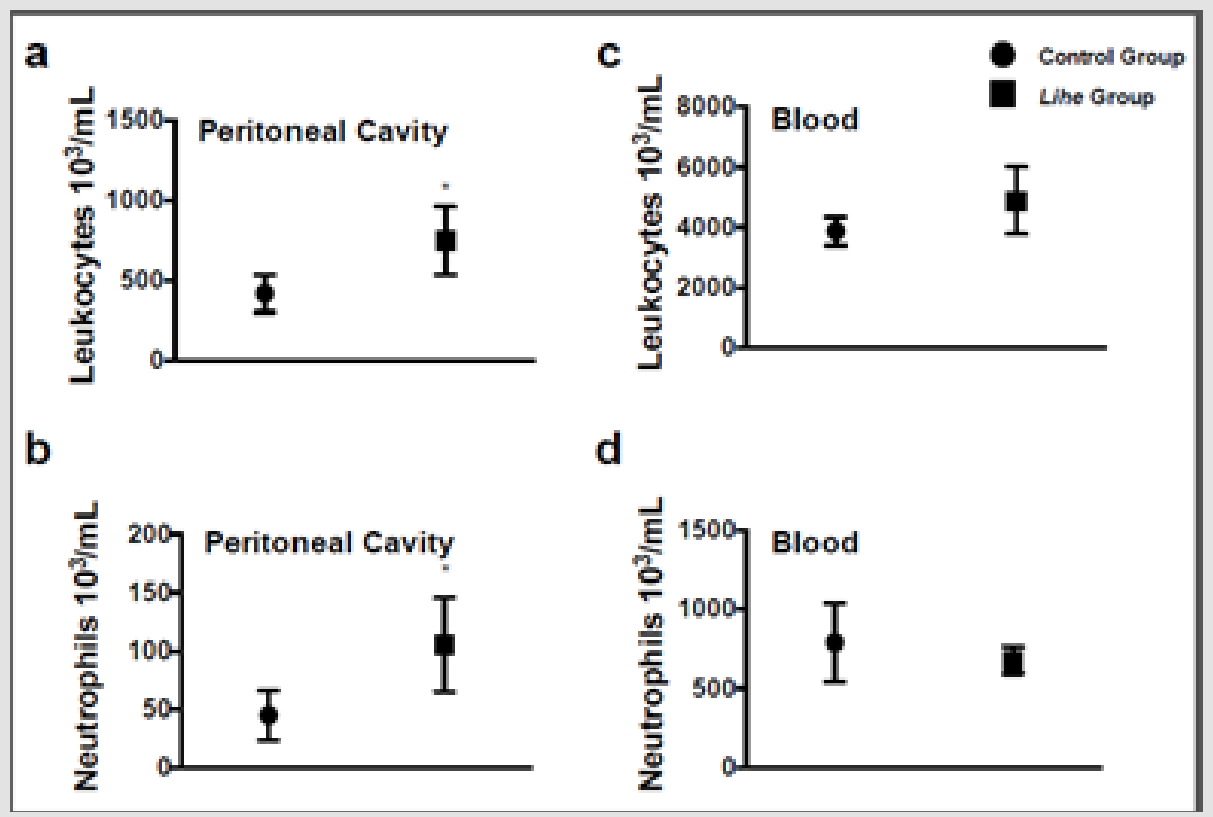

Figure 2: Lihe induces cell recruitment into the peritoneal cavity under physiological conditions. Mice received $100 \mu \mathrm{L}$ of vehicle (control group) or Lihe $(300 \mathrm{mg} / \mathrm{kg}$, v.o.) every 5 days for 30 days. The control group received the received water (100 $\mu \mathrm{L}$, v.o.), containing the same amount of alcohol present in the extract. Total leukocytes ( $\mathrm{a}$ and $\mathrm{c}$ ) and neutrophils (b and d) were counted after 30 days of administration. The experiment was conducted twice using seven mice per group, and error bars denote \pm SEM.

*Control group versus Lihe group. Differences were considered significant with $\mathrm{p}<0.05$ according to two-tailed Student's t-test. 


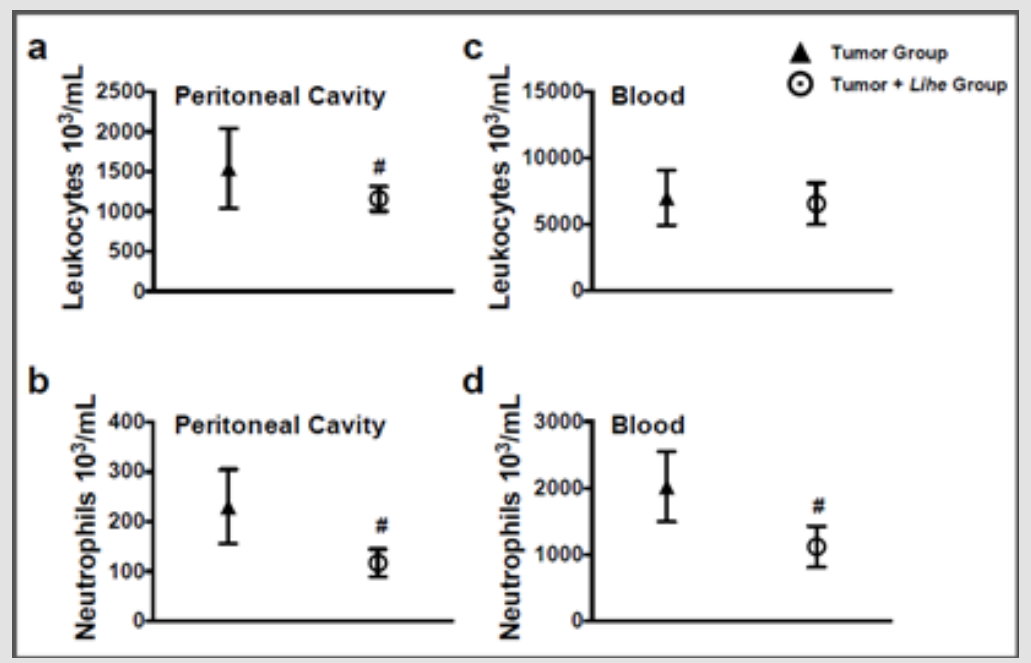

Figure 3: Lihe decreases cellular infiltration and circulation during experimental melanoma. The number of total leukocytes ( $a$ and c) and neutrophils ( $b$ and d) were evaluated after 30 days of the subcutaneous inoculation of B16F10 melanoma cells (concentration of $10^{6}$ cells $/ \mathrm{mL}$ of $0.9 \%$ saline solution $\left./ 0.1 \mathrm{~mL}\right)$. The animals received Lihe $(300 \mathrm{mg} / \mathrm{kg} / 100 \mu \mathrm{L}$, v.o.) or vehicle every 5 days for 30 days. The experiment was conducted twice using seven mice per group, and error bars denote \pm SEM.

*Tumor group versus tumor + Lihe group. These differences were considered significant with $\mathrm{p}<0.05$ according to two-tailed Student's t-test.

\section{Lihe Reduces Edema and Inflammatory Cytokines \\ During Experimental Melanoma}

Augmented proteins in the extravascular space are a consequence of increased vascular permeability, and its quantification is used as an evidence of edema formation. Lihe treatment of Balb/c mice significantly reduced the protein content on the peritoneal cavity under physiological conditions (Figure 4a). Furthermore, inoculation of B16F10 melanoma cells increased the protein content on the peritoneal cavity, whereas Lihe treatment significantly reduced protein concentration in the peritoneal cavity (Figure 4b), suggesting that it had a significant impact on edema formation. Cytokines are important for cell recruitment and edema formation during the inflammatory response. Therefore, we evaluated the impact of Lihe treatment on the production of inflammatory cytokines. Interestingly, Lihe treatment significantly decreased the concentration of IL-6 (Figure 5a), TNF- $\alpha$ (Figure 5b) and IL-1 $\beta$ (Figure $5 \mathrm{c}$ ) in the peritoneal cavity of animals inoculated with B16F10 melanoma cells.

\section{Lihe Decreases Tumor Growth and Reduces Mortality in Tumor-Group}

Tumor growth was monitored every 5 days for 30 days after implantation of B16F10 melanoma cells. Lihe treatment significantly decreased the size of the tumor when compared to the group of mice that received only vehicle (Figure 6a and 6b).
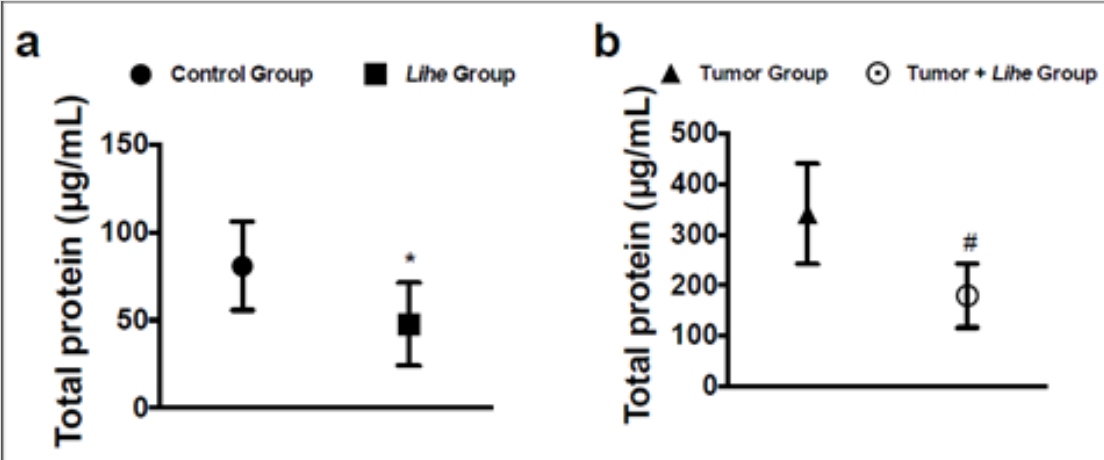

Figure 4: : Lihe decreases edema in tumor-group mice. Total protein was measured in the peritoneal fluid after 30 days of vehicle or Lihe treatment of non-tumor Balb/c mice (a); or after 30 days of subcutaneous inoculation of B16F10 melanoma cells (concentration of $10^{6}$ cells $/ \mathrm{mL}$ of $0.9 \%$ saline solution $\left./ 0.1 \mathrm{~mL}\right)$ in Balb/c mice that received Lihe $(300 \mathrm{mg} / \mathrm{kg} / 100 \mu \mathrm{L}$, v.o.) or vehicle (b). Total protein was quantified by Coomassie protein method. The experiment was conducted twice using seven mice per group, and error bars denote \pm SEM.

*Control group versus Lihe group; \#tumor group versus tumor + Lihe group. These differences were considered significant with $\mathrm{p}<0.05$ according to two-tailed Student's t-test. 


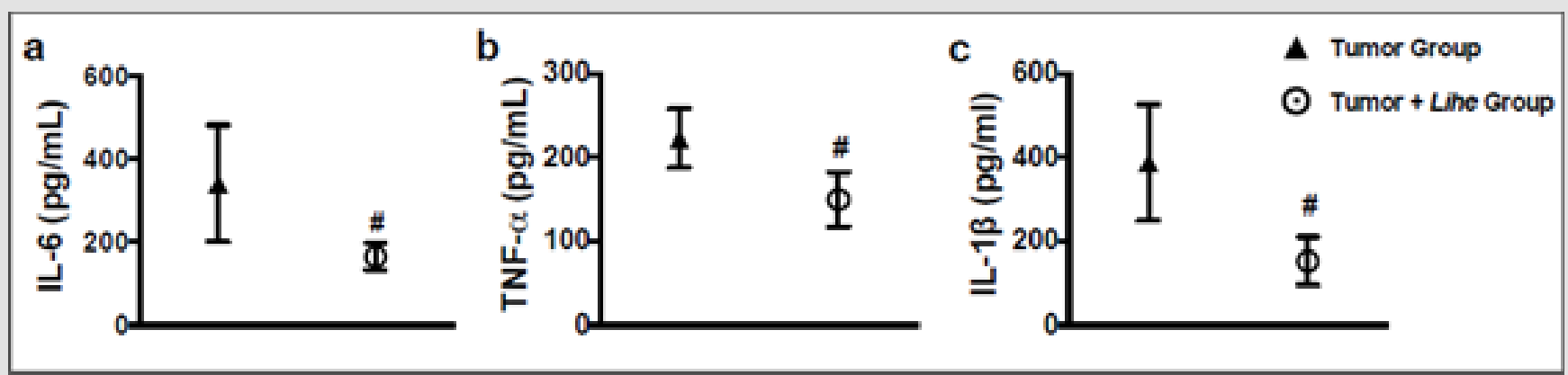

Figure 5: Lihe decreases inflammatory cytokines in mice harboring melanoma. IL-6 (a), TNF- $\alpha$ (b) and IL-1 3 (c) were measured in the peritoneal fluid after 30 days of the subcutaneous inoculation of B16F10 melanoma cells (concentration of $10^{6}$ cells $/ \mathrm{mL}$ of $0.9 \%$ saline solution $/ 0.1 \mathrm{~mL})$. The animals received Lihe $(300 \mathrm{mg} / \mathrm{kg} / 100 \mu \mathrm{L}$, v.o.) or water $(100 \mu \mathrm{L}$, v.o. $)$, containing the same amount of alcohol present in the extract every 5 days for a month. Cytokines was quantified by ELISA method. The experiment was conducted twice using seven mice per group, and error bars denote \pm SEM.

*Tumor group versus tumor + Lihe group. These differences were considered significant with $p<0.05$ according to two-tailed Student's t-test.
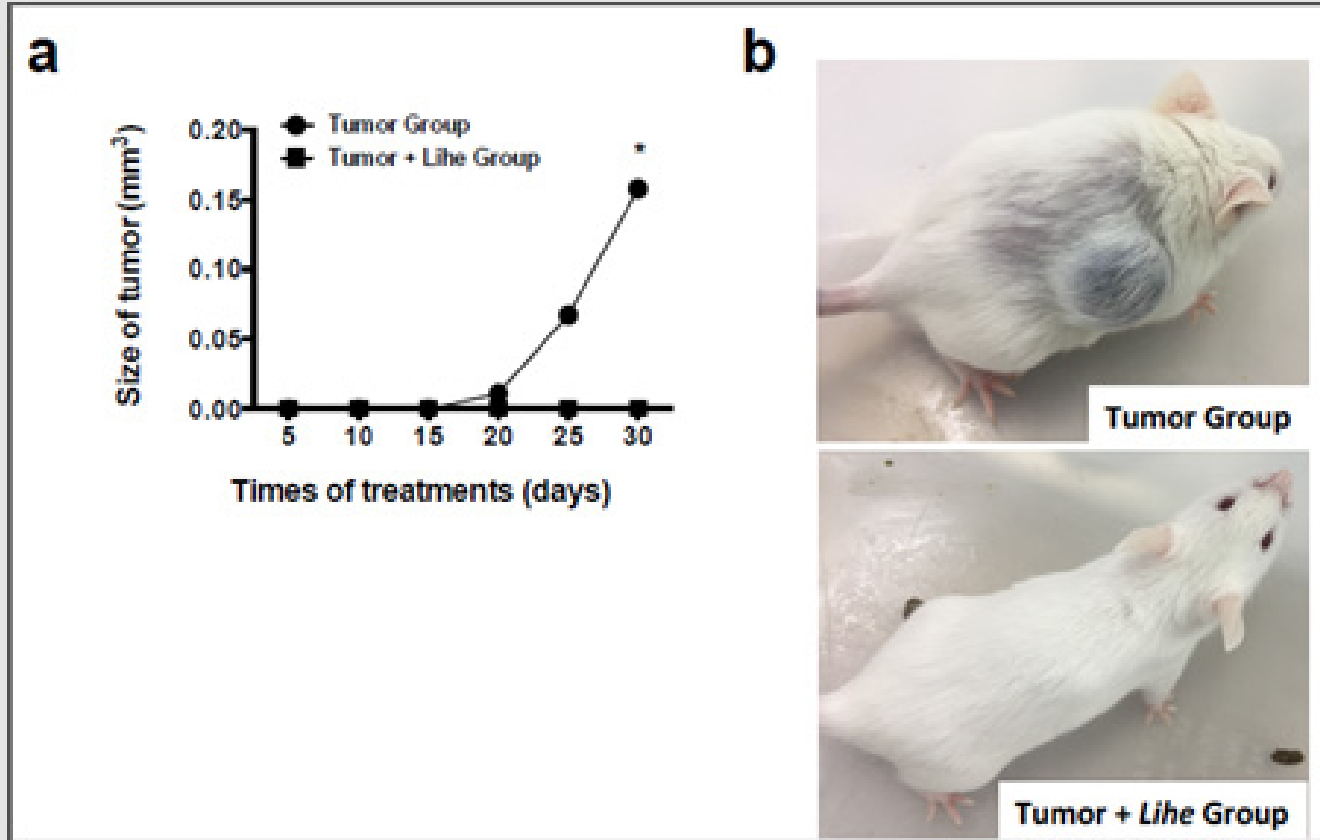

Figure 6: Lihe treatment significantly reduces melanoma growth. For assessment of tumor size (a and b), the animals were subcutaneously inoculated with B16F10 cells melanoma (concentration of $10^{6}$ cells $/ \mathrm{mL}$ of $0.9 \%$ saline solution/0.1 mL) and received Lihe $(300 \mathrm{mg} / \mathrm{kg}$, v.o.) or vehicle after every 5 days for a month. The experiment was conducted twice, and error bars denote \pm SEM.

*Tumor group versus tumor + Lihe group. These differences were considered significant with $\mathrm{p}<0.05$ according to ANOVA with Tukey's post-test.

\section{Discussion}

In this study we analyzed the inflammatory process induced by the B16F10 melanoma tumor cells in mice and how this was affected by the oral administration of the Lihe. Inflammation is a critical process that can initiate and/or propagate carcinogenesis. Tumor cells are capable of producing factors that attract leukocytes to the tumoral environment. In addition to localizing within tumor aggregates, immune cells are frequently present within the stromal microenvironment that sustains tumors [23]. Neutrophils play a significant role during this process [1]. Ours results showed that the recruitment of neutrophils was significantly reduced by the administration of the plant extract during the experimental mouse model of melanoma. These data indicate that Lihe modulates the inflammatory response, which can be important to tumor maintenance and progress. A four-step mechanism is believed to coordinate recruitment of neutrophils. These steps involve: activation of members of the selectin family of adhesion molecules (L- P- and E-selectin); triggering of signals that activate 
and upregulate leukocyte integrins mediated by cytokines and leukocyte-activating molecules; immobilization of neutrophils on the surface of the vascular endothelium by means of tight adhesion through $\alpha 4 \beta 1$ and $\alpha 4 \beta 7$ integrins binding to endothelial vascular cell-adhesion molecule-1 (VCAM-1) and MadCAM-1, respectively; and transmigration through the endothelium to sites of injury, presumably facilitated by extracellular proteases, such as Matrix Metallo Proteinases (MMPs) [24].

The extravasation of proteins occurs due to the increase in vascular permeability, which is typical of the inflammatory process caused by the tumoral activity $[1,16,23]$. Our results showed a reduction in protein levels in all the animals treated with the extract, providing further evidence for a reduction of the inflammatory process during tumoral activity. Cytokines are secreted or membrane-bound proteins that regulate the growth differentiation and activation of immune system [25]. The cellular alterations that give rise to cancer provoke changes in local cytokine expression. These perturbations stimulate immune-cell infiltrates, which, in turn, release additional cytokines that act in an autocrine or paracrine manner. These host reactions to cellular stress can impact several stages of cancer formation and progression [26]. TNF- $\alpha$ is a well-known pro-inflammatory cytokine and a major inducer of NF- $\kappa \mathrm{B}$ transcription factor, a key regulator of oncogenesis $[27,28]$. Activation of NF- $\kappa B$ promotes cellular proliferation and inhibits apoptosis favoring cancer development [29]. Angiogenesis is important step to tumor progression and invasion [30,31].

This process is promoted by enhanced expression of endogenous angiogenic factors, such as Interleukin-8 (IL-8), Vascular Endothelial Growth Factor (VEGF), Basic Fibroblast Growth Factor (BFGF) and transforming growth factor $\alpha$, and by decreased expression of angiogenic inhibitors, such as interferon- $\alpha / \beta$, platelet factor- 4 , thrombospondins and angiostatin [32]. Melanoma cells produce multiple cytokines and growth factors, including transforming growth factor $\beta$, Acidic Fibroblast Growth Factor, AFGF, plateletderived growth factor, IL-8, TNF- $\alpha$, IL-1, IL-6, VEGF and interferons, some of which have potent angiogenic activity and consequently potentiate neoplastic progression [26,33]. Ours results showed that levels of TNF- $\alpha$, IL- 1 and IL- 6 were significantly reduced by the administration of the plant extract on mice with tumor cells. Since these cytokines have important roles in tumor progression and invasion, this result represents an important anti-inflammatory and anti-tumoral of our study plant. The main components of our study plant, Lobelia inflata are the alkaloids [34]. Many alkaloids with anti-inflammatory properties have been described. For example, Bukitingina, an alkaloid obtained from Sapium baccatum (Euphorbiaceae), showed anti-inflammatory potential in carrageenan-induced paw edema, and decreased levels of PGE2 and leukocyte infiltration in the carrageenan-induced pleurisy model $[35,36]$; Berberine, another alkaloid found in species belonging to the genus Berberies (Berberidaceae) presents promising antiinflammatory activity by reducing both paw edema and vascular permeability in inflammatory models [36,37]; Theacrine is an alkaloid obtained from Camelia kucha, a plant endemic to China, that presents pharmacological activity on the nervous system such as sedation and hypnosis, besides a potential anti-inflammatory activity [38].

Many plant alkaloids also have proven antitumoral activity with several mechanisms of action such as: Catharanthus roseus (L.) G. Don, also known such as Vinca, which has compounds that are capable of stimulating depolarization of the microtubules [39]. Paclitaxel, a polyhydroxylated triterpene obtained from Taxus brevifolia, a Pacific tree, which obtained positive results against a wide variety of tumors at nano-molar concentrations such as the breast and ovarian tumor due to its ability to inhibit tubulin depolarization [40,41]; Camptothecin is an alkaloid extracted from Camptotheca acuminata Decne (Cornaceae), with topoisomerase I inhibition activity and has been approved for the treatment of colon cancer, and later to the lung and ovary, among others [42].

\section{Conclusion}

In conclusion, administration of the hydroalcoholic extract of the L. inflata plant reduced the recruitment of inflammatory cells, edema and inflammatory cytokines (IL-1, IL-6 and TNF- $\alpha$ ) in the peritoneal cavity and had a striking impact on tumoral growth. These results demonstrate that the extract of the L. inflata plant shows significant antitumoral activity. More detailed studies can better elucidate the compounds and antitumoral mechanisms of this plant extract and contribute to the development of new treatment for melanoma.

\section{Funding}

This research was funded by Barão de Mauá University Center.

\section{Author Contributions}

Conceptualization and design K.F.Z.; Performed the experiments, NPG, LCI, C.T.S. and K.F.Z.; Formal analysis, all authors; Data interpretation, MPC, L.G.G., L.H.F., C.T.S. and K.F.Z., Writingoriginal draft preparation, L.G.G. and K.F.Z.; Critical revision of the manuscript: all authors.

\section{Acknowledgment}

We are grateful to Prof. Dr. Milton Groppo (University of Sao Paulo) for analysis and identification of Lobelia inflata; and Mirella $S$ Reis for providing Lobelia inflata extract.

\section{Conflict of Interest}

The authors declare no conflicts of interest.

\section{References}

1. Medzhitov R (2008) Origin and physiological roles of inflammation. Nature 454(7203): 428-435.

2. Coussens LM, Z Werb (2002) Inflammation and cancer. Nature 420 (6917) 860-867. 
3. Lopes FC, Rocha A, Pirraco A, Regasini LO, Silva DH, et al. (2009) Antiangiogenic effects of pterogynidine alkaloid isolated from Alchornea glandulosa. BMC Complement Altern Med 9: 15.

4. Sethi G, Shanmugam MK, Ramachandran L, Kumar AP, Tergaonkar V (2012) Multifaceted link between cancer and inflammation. Biosci Rep 32(1): 1-15.

5. Allavena P, Garlanda C, Borrello MG, Sica A, Mantovani A (2008) Pathways connecting inflammation and cancer. Curr Opin Genet Dev 18(1): 3-10.

6. Allavena P, Sica A, Solinas G, Porta C, Mantovani A (2008) The inflammatory micro-environment in tumor progression: the role of tumor-associated macrophages. Crit Rev Oncol Hematol 66(1): 1-9.

7. Urban JL, Shepard HM, Rothstein JL, Sugarman BJ, Schreiber H (1986) Tumor necrosis factor: a potent effector molecule for tumor cell killing by activated macrophages. Proc Natl Acad Sci USA 83(14): 5233-5237.

8. Stuehr DJ, CF Nathan (1989) Nitric oxide: A macrophage product responsible for cytostasis and respiratory inhibition in tumor target cells. J Exp Med 169(5): 1543-1555.

9. Mytar B, Siedlar M, Wołoszyn M, Ruggiero I, Pryjma J, et al. (1999) Induction of reactive oxygen intermediates in human monocytes by tumour cells and their role in spontaneous monocyte cytotoxicity. Br J Cancer 79(5-6): 737-743.

10. Bonnotte B, Larmonier N, Favre N, Fromentin A, Moutet M, et al. (2001) Identification of tumor-infiltrating macrophages as the killers of tumor cells after immunization in a rat model system. J Immunol 167(9): 50775083.

11. Tucker MA, AM Goldstein (2003) Melanoma etiology: where are we? Oncogene 22(20): 3042-3052.

12. Janeway CA, R Medzhitov (2002) Innate immune recognition. Annu Rev Immunol 20: 197-216.

13. Lourenco AM, LM Ferreira, PS Branco (2012) Molecules of natural origin, semi-synthesis and synthesis with anti-inflammatory and anticancer utilities. Curr Pharm Des 18(26): 3979-4046.

14. Yang R, Yuan BC, Ma YS, Zhou S, Liu Y (2017) The anti-inflammatory activity of licorice, a widely used Chinese herb. Pharm Biol 55(1): 5-18.

15. Bhattacharya S (2017) Medicinal plants and natural products in amelioration of arsenic toxicity: a short review. Pharm Biol 55(1): 349354.

16. Nascimento BAC, Gardinassi LG, Silveira IMG, Gallucci MG, Tomé MA, et al. (2019) Arctium lappa Extract Suppresses Inflammation and Inhibits Melanoma Progression. Medicines 6(3).

17. Folquitto DG, Swiech JND, Pereira CB, Bobek VB, Halila Possagno GC et al. (2019) Biological activity, phytochemistry and traditional uses of genus Lobelia (Campanulaceae): A systematic review. Fitoterapia 134: 23-38.

18. Karawya MS, SM Abdel Wahab, AY Zaki (1971) Colorimetric method for the estimation of alkaloids in lobelia and its pharmaceutical preparations. J Assoc Off Anal Chem 54(6): 1423-1425.

19. Chen MW, Chen WR, Zhang JM, Long XY, Wang YT (2014) Lobelia chinensis: chemical constituents and anticancer activity perspective. Chin J Nat Med 12(2): 103-107.

20. Li KC, Ho YL, Huang GJ, Chang YS (2015) Anti-oxidative and antiinflammatory effects of Lobelia chinensis in vitro and in vivo. Am J Chin Med 43(2): 269-287.

21. Cui X, X Gu, W Kang (2016) Antioxidant Activity in Vitro and Hepatoprotective Effects in Vivo of Compound Lobelia. Afr J Tradit Complement Altern Med 13(5): 114-122.

22. Looney WB, Mayo AA, Janners MY, Mellon JG, Allen P, et al. (1971) Cel proliferation and tumor growth in hepatomas 3924A. Cancer Res 31(6): 821-825.
23.Wang J, Danyang Li, Bo Guo (2019) Crosstalk between cancer and immune cells: Role of tumor-associated macrophages in the tumor microenvironment. Cancer Med 8(10): 4709-4721.

24. Mitroulis, I, Alexaki VI, Kourtzelis I, Ziogas A, Hajishengallis G, et al. (2015) Leukocyte integrins: role in leukocyte recruitment and as therapeutic targets in inflammatory disease. Pharmacol Ther 147: 123135.

25. Arango Duque G, A Descoteaux (2014) Macrophage cytokines: involvement in immunity and infectious diseases. Front Immunol 5: 491.

26. Esquivel Velazquez M, Ostoa Saloma P, Palacios Arreola MI, Nava Castro KE, Castro JI, et al. (2015) The role of cytokines in breast cancer development and progression. J Interferon Cytokine Res 35(1): 1-16.

27. Yin Y, X Chen, Y Shu (2009) Gene expression of the invasive phenotype of TNF-alpha-treated MCF-7 cells. Biomed Pharmacother 63(6): 421-428.

28. Baumgarten SC, J. Frasor (2012) Minireview: Inflammation: an instigator of more aggressive estrogen receptor (ER) positive breast cancers. Mol Endocrinol 26(3): 360-371.

29. Connelly L, Barham W, Onishko HM, Sherrill T, Chodosh LA, et al. (2011) Inhibition of NF-kappa B activity in mammary epithelium increases tumor latency and decreases tumor burden. Oncogene 30(12): 14021412

30. Risau W (1997) Mechanisms of angiogenesis. Nature 386(6626): 671674.

31. Carmeliet P (2000) Mechanisms of angiogenesis and arteriogenesis. Nat Med 6(4): 389-395.

32. Rajabi M, SA Mousa (2017) The Role of Angiogenesis in Cancer Treatment. Biomedicines 5(2): 34.

33. Mattei S, Colombo MP, Melani C, Silvani A, Parmiani G, et al. (1994) Expression of cytokine/growth factors and their receptors in human melanoma and melanocytes. Int J Cancer 56(6): 853-857.

34. Yang S, Shen T, Zhao L, Li C, Zhang Y, et al. (2014) Chemical constituents of Lobelia chinensis. Fitoterapia 93: 168-174.

35. Panthong A, Kanjanapothi D, Thitiponpunt Y, Taesotikul T, Arbain D (1998) Anti-inflammatory activity of the alkaloid bukittinggine from Sapium baccatum. Planta Med 64(6): 530-535.

36. Ribeiro VP, Arruda C, Abd El Salam M, Bastos JK (2018) Brazilian medicinal plants with corroborated anti-inflammatory activities: a review. Pharm Biol 56(1): 253-268.

37. Kupeli E, Koșar M, Yeșilada E, Hüsnü K, Bașer C (2002) A comparative study on the anti-inflammatory, antinociceptive and antipyretic effects of isoquinoline alkaloids from the roots of Turkish Berberis species. Life Sci 72(6): 645-657

38. Wang Y, Yang X, Zheng X, Li J, Ye C, et al. (2010) Theacrine, a purine alkaloid with anti-inflammatory and analgesic activities. Fitoterapia 81(6): 627-631.

39. Starobova H, I Vetter (2017) Pathophysiology of Chemotherapy-Induced Peripheral Neuropathy. Front Mol Neurosci 10: 174.

40. Rowinsky EK, LA Cazenave, RC Donehower (1990) Taxol: a novel investigational antimicrotubule agent. J Natl Cancer Inst 82(15): 12471259.

41. Tabata H (2006) Production of paclitaxel and the related taxanes by cell suspension cultures of Taxus species. Curr Drug Targets 7(4): 453-461.

42. Venditto VJ, EE Simanek (2010) Cancer therapies utilizing the camptothecins: a review of the in vivo literature. Mol Pharm 7(2): 307349. 
ISSN: 2574-1241

DOI: 10.26717/BJSTR.2020.25.004154

Karina Furlani Zoccal. Biomed J Sci \& Tech Res

cC) This work is licensed under Creative

Submission Link: https://biomedres.us/submit-manuscript.php

$\begin{array}{ll}\text { BIOMEDICAL } & \text { Assets of Publishing with us } \\ \text { RESEARCHES } & \text { - Global archiving of articles } \\ \text { - Immediate, unrestricted online access }\end{array}$

